\title{
Differentiating Benign from Suspicious Vertebral Marrow Lesions Detected with Conventional Magnetic Resonance Imaging Using Apparent Diffusion Coefficient and Diffusion-Weighted Image
}

\author{
Khaleel Ibraheem Mohson ${ }^{1 *}$, Qusay Tayser Naief ${ }^{2}$, Farah Abdul Jalil ${ }^{1}$ \\ ${ }^{1}$ National Cancer Research Center, University of Baghdad, Iraq; ${ }^{2}$ Magnetic Resonance Unit, Oncology Teaching Hospital, \\ Medical City Complex, Iraq
}

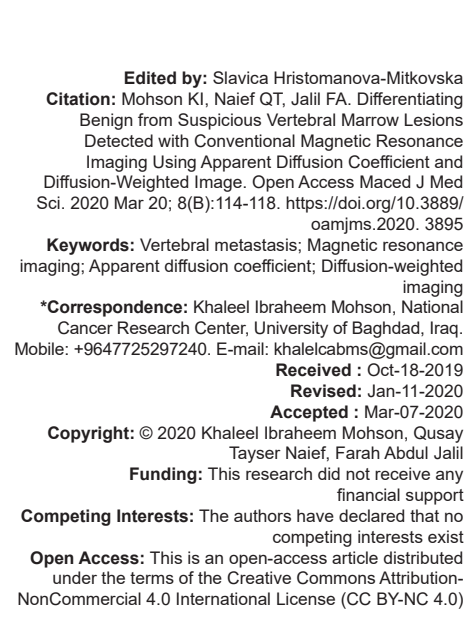

Abstract

BACKGROUND: Advanced magnetic resonance imaging (MRI) sequences, include the apparent diffusion coefficient (ADC) and diffusion-weighted imaging (DWI), are of great benefit in assessing troublesome vertebral marrow lesion in patients presented with primary malignancy outside the spines.

OBJECTIVES: The aim of the study was to evaluate the role of vertebral column MRI in characterization and evaluation of marrow lesion in patients with primary malignancy utilizing ADC and DWI in addition to conventional MRI sequences.

METHODS: This is a cross-sectional study which includes 80 patients referred to MR unit 58 of them referred from the oncology department in oncology teaching hospital having primary cancer outside the spine and also referred complaining of back pain and worry from metastasis while the remaining 22 are cancer-free patients referred to MRI because of lower back pain - the study was performed in Medical City, Baghdad, Iraq, during the period from the beginning of September 2018-October 2019

RESULTS: The study sample consists of 55 females and 25 males, the breast cancer is main primary in females and represents $30 / 58$ patients, while the prostate is the main cancer in males and represents $7 / 58$ patients. When correlating the MR sequences (T1W, Fat sat and DWI) all together and after addition of ADC value $\left(<9 \times 10^{-3} \mathrm{~mm}^{2} / \mathrm{sec}\right)$ in diagnosis of malignancy there is decreasing frequency of positive cases from $39 \%$ before ADC to $22.4 \%$ after adding it which is close to histopathology results (17\%). The sensitivity, specificity, positive predictive value, negative predictive value, and overall accuracy of ADC in detecting metastasis within the vertebral marrow are $94 \%, 95 \%$, $88.9 \%, 97.5 \%$, and $94.8 \%$, respectively.

CONCLUSION: Conventional MRI using standard T1W, T2 weighted, and fat suppression sequences cannot discriminate between benign and pathological vertebral marrow lesions. Using DWI improves the recognition of pathological bony lesion(s) and this is strengthened when enforced by ADC value and by that, it can replace the need for intravenous contrast administration. DWI and ADC are beneficial in follow-up of previously detected restricted lesion and in assessment its response to treatment that was depicted by measuring its ADC that consequently elevated in healing phase.

\section{Introduction}

Unluckily metastatic disease to bone which is mainly affect the axial skeleton (vertebral body, iliac bone, the proximal femora, and humeri) is a common squeal in many cancers as early or late presentation of the disease [1]. The presence of marrow metastasis has a great effect on the treatment plan, because its development was considered Stage IV, and here, only palliative treatment will be used in most cases [2]. Once bone metastasis occurs that there is dispersed morbidity from the neurological or stability problems and limitation of patient life from severe pain [3].

For that the characterization of the bony lesion in patients with primary malignancy is very important, this is broadly done using magnetic resonance imaging
(MRI), the conventional MRI can detect the lesion and delineate it clearly from nearby normal marrow, but has limitation in predicting whether this lesion is benign or malignant [4] so the introduction of functional MRI that includes apparent diffusion coefficient (ADC) maps and diffusion-weighted imaging (DWI) can do this job and predict the nature of the lesion, especially when calculating the ADC value of the lesion [5].

Primarily, the DWI was established in the imaging of the central nervous system's abnormalities [6]. With time, this MRI sequence has been used for variable body systems and examinations, mainly in the oncology patients [7].

Regarding our research, we focus the light on the appearance of variable bony lesions affecting the spine, some of them are common and are not neoplastic as typical hemangioma; here, the diagnosis is straight 
forward while others are problematic as atypical hemangioma which leads to diagnostic dilemma in differentiating it from bony Mets [8].

The main principle of DWI technique is the regulations of free water transport in the cellular compartment, according to Brownian motion(9), by that DWI able to detect abnormal tissue by assessing the quantity of water within, the more compacted cells, the more limiting to water particles movement when compared with normal nearby tissues, this is opposing to the tissues with low cellular content or necrotic where disturbed cell membranes are predominant, diffusion is not restricted [10].

DWI is a spin-echo T2-weighted single-shot sequence that originates from two symmetric

motion gradient pulses about a $180^{\circ}$ refocusing pulse, so the moving water particles do not realign and exhibit a signal drop on DWI, while the water molecules interposed by cellular membranes or intracellular component gain the signal and show high signal on DWI [11].

DWI and ADC values have been offered for the discernment between the malignant deposit, especially in patients with primary condition [12], in general, the bone marrow metastases appear as a high signal area on DWI within low signal normal vertebral marrow, while in ADC, it appears as low signal within relatively high signal normal vertebral marrow [13].

\section{Materials and Methods}

This study included 80 patients referred to magnetic resonance (MR) unit from the oncology department in oncology teaching hospital - Medical City, Baghdad, Iraq, during the period from the beginning of September 3, 2019- July 7,2019.

All patients had a history of primary malignant tumor outside the bone marrow and complaining of back pain or symptoms related to spinal cord compression or having neurological deficit, those patients then subjected MRI examination of the spine, including the lumbar or thoracolumbar areas, using Avanto 1.5T closed MRI system Siemens (Germany).

The MRI protocols include sagittal T1-weighted (T1W) spin echo (SE), sagittal T2-weighted (T2W) SE, sagittal T2W fat suppression SE, and axial T2W SE.

After that, the DWIs were taken in the sagittal plane using a single-shot echo-planar sequence. The b values were 0,500 , and $800 \mathrm{~s} / \mathrm{mm}^{2}$. DWls were also obtained in sagittal plane.

After obtaining these images, full analysis of pathological findings was done by reviewing the T1 and T2 images and doing three-dimensional references to allocated the position of the lesion in ADC and DW sequences, the signal of the lesion is recorded in all sequences, and the brightness of the suspicious lesion is seen on DW and its ADC value was calculated.

Diagnosis of metastasis is established either by biopsy or radioisotope using bone scan or positron emitting tomography, all these with Mets had follow-up by repeating the MRI examination 3-6 months after initiation of chemo- or radiotherapy.

\section{Statistical analysis}

All the relevant data were entered using computerized statistical software; Statistical Package for the Social

Sciences (SPSS) version 20. Descriptive statistics presented as mean \pm standard deviation and frequencies as percentages.

\section{Results}

This is a cross-sectional study which includes 80 patients and four of them had follow-up study, 22 of them are cancer-free patients referred to MRI because of lower back pain, and the remaining 58 patients had primary cancer outside the spine and also referred complaining of back pain and worry from metastasis.

The study samples consist of 55 females and 25 males, the breast cancer is the main primary in females and represents $29 / 58$ patients, while the prostate cancer is the main cancer in male and represents 6/58 patients. Details of age, gender, and cancer types are illustrated in Table 1.

The MR examination in the control group is normal in $18 / 22$ patients, the remaining four reveal

Table 1: Age, gender, and cancer types of the study population

\begin{tabular}{ll}
\hline Age groups & Number $(\%)$ \\
\hline Age & $14(17.5)$ \\
$<40$ years & $15(18.75)$ \\
$41-49$ & $21(26.25)$ \\
$50-59$ & $22(27.5)$ \\
$60-69$ & $8(10)$ \\
$>70$ & $80(100)$ \\
Total & \\
Gender & $25(31.25)$ \\
Males & $55(68.75)$ \\
Females & $80(100)$ \\
Total & \\
Cancer type & \\
Females & $29(72.5)$ \\
Breast & $3(7.5)$ \\
Ovary & $3(7.5)$ \\
Uterus & $5(12.5)$ \\
Other & $40(100)$ \\
Total & \\
Males & $6(46)$ \\
Prostate & $2(15.5)$ \\
Lung & $5(38.5)$ \\
Other & $13(100)$ \\
Total & \\
\hline
\end{tabular}


typical hemangioma in two, atypical hemangioma in one, and Modic I end plate changes in the last one.

While the examination of the patients with primary cancer reveals metastasis in 14/58, the remaining findings are discussed briefly in Table 2.

Table 2: MRI findings in control group and cancer patients

\begin{tabular}{ll}
\hline MRI findings & Number (\%) \\
\hline Control group & $18(81.8)$ \\
Normal & $2(9.1)$ \\
Typical hemangioma & $1(4.54)$ \\
Modic I & $1(4.54)$ \\
Atypical hemangioma & $22(100)$ \\
Total & \\
Patients & $14(24.1)$ \\
Metastasis & $17(29.3)$ \\
Free of metastasis & $9(15.5)$ \\
Inactive & $7(12.06)$ \\
Typical and atypical hemangioma & $3(5.17)$ \\
Modic changes & $5(8.6)$ \\
Fracture & $1(1.7)$ \\
Collection & $2(3.4)$ \\
Others & $58(100)$ \\
Total &
\end{tabular}

The correlation between T1W images and Fatsat sequence, on the one hand, with DWI results, on the other hand, in cases of malignant findings revealed that low signal lesions on T1, and high Fatsat and DWI seen in $23 / 58(39.6 \%)$ of those only $10(17 \%)$ patients are really metastasis, while when adding the low ADC value $\left(<9 \times 10^{-3} \mathrm{~mm}^{2} / \mathrm{s}\right)$ to previous parameters, the metastasis percentage decreases from $39.6 \%$ to $22.4 \%$ $(13 / 58)$.

The sensitivity, specificity, positive predictive value (PPV), negative predictive value (NPV) and overall accuracy of ADC in detecting metastasis within the vertebral marrow are illustrated in Table 3.

Table 3: Sensitivity, specificity, positive predictive and negative value, and overall accuracy of ADC in detecting metastasis

\begin{tabular}{|c|c|c|c|}
\hline ADC value & Metastasis present & Metastasis absent & Total \\
\hline Low & $16 / 84^{*}$ & $2 / 84$ & 18 \\
\hline Normal or high & $1 / 84^{*}$ & $39 / 84^{*}$ & 40 \\
\hline Total & 17 & 41 & \\
\hline \multicolumn{4}{|c|}{$\begin{array}{l}\text { *The total number of patients increased to } 84 \text { because four of the patients had two pathology, } 1^{\text {st }} \text { is patient with } \\
\text { Ewing sarcoma and had collection (abscess as well), two patients are the elderly with prostate cancer and had } \\
\text { active and inert bony lesion, and finally, a patient with breast cancer and also had active and inert lesion. }\end{array}$} \\
\hline & Value (\%) & \multicolumn{2}{|c|}{$95 \%$ confidence interval $(\mathrm{Cl})$} \\
\hline Sensitivity & 94.12 & \multicolumn{2}{|c|}{$71.31-99.85$} \\
\hline Specificity & 95.12 & \multicolumn{2}{|l|}{$83.47-99.40$} \\
\hline PPV & 88.89 & \multicolumn{2}{|l|}{$67.32-96.88$} \\
\hline NPV & 97.50 & \multicolumn{2}{|l|}{$85.33-99.62$} \\
\hline Accuracy & 94.83 & \multicolumn{2}{|l|}{$85.62-98.92$} \\
\hline
\end{tabular}

\section{Discussion}

The introduction of diffusion-weighted MRI revolutionized the diagnosis of benign and malignant vertebral tumors in addition being non-invasive technique, this was achieved by considering the low signal lesion as benign and the high signal one as malignant, on the other hand, the high signal on ADC is more in keeping with a benign cause [14].
Before the DWI was introduced, it was difficult to diagnose the lesion, whether being metastatic or benign tumors using the T1W and T2W images and even with using the fat saturation sequence, the latter only highlighting the hidden lesion that could not clearly visualized in the T1W and T2W sequences. The intravenous contrast injection did not add anything to the diagnosis because many numbers of benign lesions took the contrast and by that, it was not solving this problem.

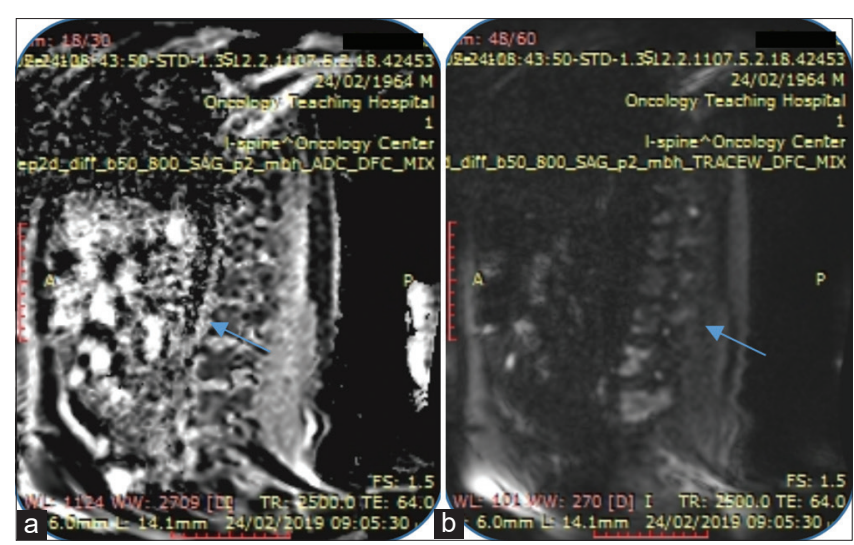

Figure 1: 55 years age female patient with history of breast cancer her MRI reveals (a) ADC image shows low signal in 4th and 5th lumber vertebral bodies (arrows )ADC (6x10-3 mm2 / sec) (b) DWI image shows restricted signal within the corresponding vertebral body ( $800 \mathrm{~s} / \mathrm{mm} 2$ )-histopathology diagnosis

However, after the entry of the ADC and the DW sequences, the problem was nearly solved, so when the lesion appeared of high signal on DWI, we compare that to it to corresponding ADC signal, if it is high on DWI and low on ADC, this raises the suspicious of malignant tumor.

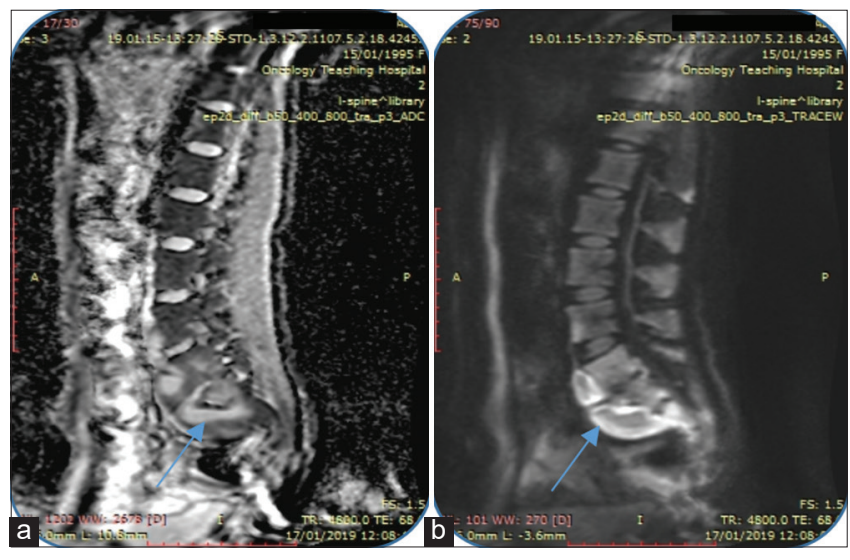

Figure 2: 35 years age female patient with history of Ewing sarcoma, her MRI reveals paravertebral abscess (a) ADC sagittal image shows low signal rim collection around 5th lumber and 1st sacral vertebral bodies (arrows) with ADC ( $3 \times 10-3 \mathrm{~mm} 2 / \mathrm{sec})$ (b) DWI:restricted signal within the rim of collection

In addition to the role of ADC mainly in the follow-up of cancer cases after treatment with chemotherapy, radiotherapy, or hormonal therapy, the response will be indicated by changing the low ADC value to high while the DWI signal either still high or reverse to low. 
In our study, the ADC value in detection bony metastasis shows high sensitivity of $94 \%$, specificity of $95 \%$, and overall accuracy of $94 \%$ and this nearly in line with a study done by Tadros and Louka [15].

In 2016, a study showed that a sensitivity of $99 \%$, a specificity of $98 \%$, a PPV of $98 \%$, a NPV of $96 \%$, and an accuracy of $98 \%$ for the detection of bone metastatic deposits, and this is highly comparable to the results in our study [16].

Regarding the PPV and NPV of ADC value in detection of vertebral marrow secondary was $89 \%$ and $97 \%$ and these in concordance with a study done by Gong et al. [17].

\section{Conclusion}

1. Conventional MRI using standard T1W, $\mathrm{T} 2 \mathrm{~W}$, and fat suppression sequences cannot discriminate between benign and pathological vertebral marrow lesions.

2. Using DWI improves the recognition of pathological bony lesion and this is strengthened when combined with ADC value.

3. Using the above technique is nearly replacing the need intravenous contrast administration, especially in renal disease and when the contrast is not available.

4. DWI and ADC are beneficial in follow-up of previously detected restricted lesion and in assessment lesions response to the treatment.

\section{References}

1. Coleman RE, Lipton A, Roodman GD, Guise TA, Boyce BF, Brufsky AM, et al. Metastasis and bone loss: Advancing treatment and prevention. Cancer Treat Rev. 2010;36(8):615 20. https://doi.org/10.1016/j.ctrv.2010.04.003

PMid:20478658

2. Sathiakumar N, Delzell E, Morrisey MA, Falkson C, Yong M, Chia V, et al. Mortality following bone metastasis and skeletalrelated events among women with breast cancer: A populationbased analysis of U.S. Medicare beneficiaries, 1999-2006. Breast Cancer Res Treat. 2012;131(1):231-8. https://doi. org/10.1007/s10549-011-1721-x

PMid:21842243

3. Tanaka R, Yonemori K, Hirakawa A, Kinoshita F, Takahashi $\mathrm{N}$, Hashimoto J, et al. Risk factors for developing skeletalrelated events in breast cancer patients with bone metastases undergoing treatment with bone-modifying agents. Oncologist. 2016;21(4):508-13. https://doi.org/10.1634/ theoncologist.2015-0377

PMid:26975863

4. Vande Berg BC, Lecouvet FE, Michaux L, FerrantA, Maldague B,
Malghem J. Magnetic resonance imaging of the bone marrow in hematological malignancies. Eur Radiol. 1998;8(8):1335-44. https://doi.org/10.1007/s003300050548

PMid:9853210

5. Lecouvet FE, Larbi A, Pasoglou V, Omoumi P, Tombal B, Michoux N, et al. MRI for response assessment in metastatic bone disease. Eur Radiol. 2013;23(7):1986-97. https://doi. org/10.1007/s00330-013-2792-3

PMid:23455764

6. Huisman TA. Diffusion-weighted imaging: Basic concepts and application in cerebral stroke and head trauma. Eur Radiol. 2003;13(10):2283-97. https://doi.org/10.1007/ s00330-003-1843-6

PMid: 14534804

7. Subhawong TK, Jacobs MA, Fayad LM. Diffusion-weighted MR imaging for characterizing musculoskeletal lesions. Radiographics. 2014;34(5):1163-77. https://doi.org/10.1148/ rg. 345140190

PMid:25208274

8. Matrawy KA, El-Nekeidy AA, El-Sheridy HG. Atypical hemangioma and malignant lesions of spine: Can diffusion weighted magnetic resonance imaging help to differentiate? Egypt J Radiol Nucl Med. 2013;44:259-263. https://doi. org/10.1016/j.ejrnm.2013.03.001

9. Malayeri AA, El Khouli RH, Zaheer A, Jacobs MA, CoronaVillalobos CP, Kamel IR, et al. Principles and applications of diffusion-weighted imaging in cancer detection, staging, and treatment follow-up. Radiographics. 2011;31(6):1773-91. https://doi.org/10.1148/rg.316115515

PMid:21997994

10. Koh DM, Collins DJ. Diffusion-weighted MRI in the body: Applications and challenges in oncology. AJR Am J Roentgenol. 2007; 188:1622-235.

11. Neil JJ. Diffusion imaging concepts for clinicians. J Magn Reson Imaging. 2008;27(1):1-7.

PMid: 18050325

12. Wu LM, Gu HY, Zheng J, Xu X, Lin LH, Deng X, et al. Diagnostic value of whole-body magnetic resonance imaging for bone metastases: A systematic review and meta-analysis. J Magn Reson Imaging. 2011;34(1):128-35. https://doi.org/10.1002/ jmri.23697

PMid:21618333

13. Lecouvet FE, El Mouedden J, Collette L, Coche E, Danse E, Jamar $\mathrm{F}$, et al. Can whole-body magnetic resonance imaging with diffusion-weighted imaging replace Tc $99 \mathrm{~m}$ bone scanning and computed tomography for single-step detection of metastases in patients with high-risk prostate cancer? Eur Urol. 2012;62(1):68-75. https://doi.org/10.1016/j.eururo.2012.02.020 PMid:22366187

14. Mubarak F, Akhtar W. Acute vertebral compression fracture: Differentiation of malignant and benign causes by diffusion weighted magnetic resonance imaging. J Pak Med Assoc. 2011;61(6):555-8.

PMid:22204209

15. Tadros MY, Louka AL, between malignant marrow diffusion and shift DB. Discrimination between benign and malignant in vertebral marrow lesions with diffusion weighted MRI and chemical shift. Egyp J Radiol Nucl Med. 2016;47:557-69. https:// doi.org/10.1016/j.ejrnm.2016.02.007

16. Barchetti F, Stagnitti A, Megna V, Al Ansari N, Marini A, Musio D, et al. Unenhanced whole-body MRI versus PET-CT for the detection of prostate cancer metastases after primary treatment. Eur Rev Med Pharmacol Sci. 2016;20(18):3770-6.

PMid:27735042 
17. Gong J, Cao W, Zhang Z, Deng Y, Kang L, Zhu P, et al. Diagnostic efficacy of whole-body diffusion-weighted imaging in the detection of tumour recurrence and metastasis by comparison with 18F-2-fluoro-2-deoxy-D-glucose positron emission tomography o computed tomography in patients with gastrointestinal cancer. Gastroenterol Rep (Oxf). 2015;3(2):128-35. https://doi.org/10.1093/gastro/gou078 PMid:25406465 